\title{
A Review of Pragmatic Competence in BELF Interactions
}

\author{
Jialiang Chen ${ }^{1}$ \\ ${ }^{1}$ School of English for International Business, Guangdong University of Foreign Studies, Guangzhou, China \\ Correspondence: Jialiang Chen, School of English for International Business, Guangdong University of Foreign \\ Studies, Guangzhou 510420, Guangdong, China. E-mail: 20190310011@gdufs.edu.cn
}

Received: August 23, $2021 \quad$ Accepted: October 7, $2021 \quad$ Online Published: October 26, 2021

doi:10.5539/ijel.v11n6p98 URL: https://doi.org/10.5539/ijel.v11n6p98

\begin{abstract}
Globalization has transformed English from a foreign language into a lingua franca. The pragmatic paradigm and pragmatic features of English as a lingua franca (ELF), are different from those of native English, especially in the business context, defined as English as a business lingua franca (BELF), which has contributed to a series of studies on pragmatic competence, pragmatic strategies and pragmatic awareness in the (B)ELF context. Relevant studies offer insights into the pragmatic competence of BELF users, which is crucial in the accomplishment of communicative goals in business settings. This paper first reviews relevant theoretical studies on (B)ELF and evaluates their characteristics from the perspective of pragmatics. Then, the focus is placed upon the diversified features of interpersonal pragmatic competence and intercultural pragmatic competence in the BELF context, revealing that the traditional paradigm of pragmatic competence based on native English does not apply to this diversified intercultural context. This paper argues for a re-conceptualization of pragmatic competence in the BELF context and a re-examination of the institutional features of BELF interactions and the dynamics of pragmatic competence, pragmatic strategies, and pragmatic awareness in this context.
\end{abstract}

Keywords: pragmatic competence, English as a (business) lingua franca, literature review

\section{Introduction}

English is widely used by people from different linguistic and cultural backgrounds to share ideas, especially in interactions between non-native English speakers (Jenkins, 2007). Quirk (1985, p. 6), a linguist who used to insist on native English as the teaching standard, argues that with the globalization of English, those learning objectives set for English standards fail to meet the current demand for intercultural communication. Statistics show that non-native English speakers have far outnumbered native English speakers (Sewell, 2012), and the further expansion of globalization enables language users from different linguistic and cultural backgrounds to communicate in English (Björkman, 2014). These users also construct some pragmatic expressions, usually temporarily, and sociopragmatic paradigms that are different from traditional native English but can be recognized and accepted by both sides of communication based on the actual situational contexts (cf. Jenkins, 2007; Seidlhofer, 2011; Kecskes, 2013). In this intercultural context, the traditional monolingual mode of language use gradually turns to a compound paradigm of multilingual and multicultural integration and coexistence, which triggers new pragmatic features presented by communicative modes, pragmatic conventions, contextual constraints, and other factors (Ran \& Yang, 2015).

Globalization has turned English from a foreign language (EFL) into a lingua franca (ELF) (cf. Seidlhofer, 2004). The change of its social role leads to a paradigm of language use different from what is in the context of native English (McKay, 2010). Developed from English as an International Language (EIL) in the 1970s, ELF refers to "any use of English among speakers of different first languages for whom English is the communicative medium of choice, and often the only option" (Seidlhofer, 2011, p. 7). Naturally, most ELF interactions occur between second-language speakers, and native English speakers are absent in many cases (Sung, 2014). In recent years, more and more attention has been paid to language use and pragmatic features in the ELF context (Seidlhofer, 2009, 2011). Hence, the concept of ELF has provided new insights into pragmatics and intercultural studies, as well as to second language learning, teaching, testing, and so on.

ELF has attracted academic attention and becomes a significant research topic in applied linguistics (Murray, 2012). The study of ELF originated in the 1980s (Jenkins et al., 2011) and ELF has become an independent research field so far (Wen, 2012) with contributions mainly to the study of applied linguistics. This is because 
ELF research challenges the authority of English as a native language, demolishes the inappropriate practice of regarding native English as the only standard for non-native English speakers, emphasizes the role of non-native English speakers, which, to a certain extent, promotes the multiple uses of English around the world (cf. Jenkins, 2009, 2014; Seidlhofer, 2011; Wang, 2013). House (2009) points out that ELF researchers no longer pay attention to a single, hegemonic paradigm of English, but varieties of English with distinctive features. The diversity and pluralism of the regions where English is spoken have become the salient feature of English, and the scope of language use has gone beyond the Anglo-American language standards and sociocultural conventions of the core regions (cf. Chen \& $\mathrm{Li}, 2015$ ).

In recent years, some researchers have begun to include pragmatic issues in the ELF context. Most existing ELF studies have focused on phonetic features (Jenkins, 2000), lexis and syntax (Seidlhofer, 2004; Björkman, 2008), and communicative strategies (House, 1999; Björkman, 2011). It is universally acknowledged in traditional studies to take the pragmatic norms of native English speakers as the standard; nevertheless, with the increasing globalization of political, economic, technological, cultural, and informational exchanges, new theories, such as intercultural pragmatics (Kecskes, 2013, 2014), have emerged on the connotation of pragmatic competence in the ELF context. The urgent need to combine ELF research with EFL teaching practice (e.g., Seidlhofer, 2011; Baker, 2015) has been realized, which also calls for a re-examination of the traditional concept of discursive features of non-native English speakers, and a re-conceptualization of pragmatic competence (e.g., Seidlhofer, 2011; Cogo \& Dewey, 2012; Baker, 2015) to make up for the conceptual gaps in English teaching and the deficiency in understanding particular pragmatic competence in this context (Seidlhofer, 2011). Moreover, the accessibility of a lingua franca enables business to be conducted in the international market, hence making English as a business lingua franca (BLEF) prominent in the intercultural context (cf. Ku \& Zussman, 2010; Nielsen, 2019). Therefore, it is necessary to reconsider the pragmatic competence of (B)ELF users and its related research, to provide a new research perspective and reference for second or foreign language teaching, learning, and testing. Focusing on the business context, this paper reviews relevant research in this area, starting from an overview of ELF and BELF interactions, and exploring the pragmatic competence in BELF interactions, namely interpersonal pragmatic competence, and intercultural pragmatic competence, to gain some implications of the reconstruction of pragmatic competence in the BELF context.

\section{English as a (Business) Lingua Franca}

\subsection{English as a Lingua Franca}

\subsubsection{ELF: An Overview}

ELF refers to communication in English between people from different linguistic backgrounds (Seidlhofer, 2011, p. 3). Firth (1996, p. 240) defines ELF as "a 'content language' between persons who share neither a common native tongue nor a common (national) culture, and for whom English is the chosen foreign language of communication". Based on Firth's definition, Jenkins et al. (2011) and Seidlhofer et al. (2011) further propose that ELF does not exclude native English speakers. ELF is a language used by people after they acquire their native language, which always plays a constantly influential role, so ELF is always deeply imprinted by the native language and culture (Jenkins, 2006, 2014). ELF in the global context promotes the interaction and integration between English and different languages and cultures, which means that in public interactions such as international academic exchanges, business negotiations, and media reports, ELF has become a communicative resource that integrates diversified languages and cultures, and serves the personal and public needs of non-native English speakers (Graddol, 2006).

At present, there are two major views on the orientation of ELF: essentialism versus non-essentialism. From the essentialist views, ELF is a natural language "regarded as a language for communication, that is, a useful instrument for making oneself understood in international encounters. It is instrumental in enabling communication with others who do not speak one's own L1" (House, 2003, p. 559). Jenkins (2009, p. 200) also defines it as "the common language of choice, among speakers who come from different linguacultural backgrounds". The non-essentialist views, on the other hand, are formed in the process of criticizing the essentialist views. It is argued that ELF cannot be an independent entity as there are no native speakers and no inherent culture in ELF interactions (cf. Prodromou, 2007; Alptekin, 2010; Park \& Wee, 2011). The non-essentialist views hold that ELF is rooted in the interaction of different cultures with the characteristics of fluidity, flexibility, and dependence (Dewey, 2007). In short, ELF is an activity of language practice, a communicative function of language, rather than a specific language product (e.g., Canagarajah, 2007; Ferguson, 2009; Alptekin, 2013). More importantly, ELF focuses on the dynamic communicative process rather than the static communicative situation. 
Early proponents of the essentialist views have gradually shifted to the non-essentialist views. For example, Jenkins et al. (2011, p. 284) admit that "the world has become so interconnected, and English so bound up with processes of globalization, that a traditional varieties orientation is no longer viable, and that we should, instead, focus on English as fluid, flexible, contingent, hybrid and deeply intercultural". Seidlhofer (2011) emphasizes that ELF is "the communicative medium of choices among speakers of different first languages" (p. 7), which is similar to Cogo's (2012) statement that "the main purpose of ELF research today is ... to reveal some of the forms that emerge in ELF interactions in specific communities, but more importantly to highlight the pragmatic strategies speakers draw on as they collaboratively engage in communication" (p. 99). On the whole, it is the debate of different views that leads to the development of ELF research.

\subsubsection{ELF and Pragmatics}

ELF research is interconnected with pragmatics research. As Björkman (2011, p. 951) said, "when it comes to research into ELF, pragmatics has led the way". Cogo and House's (2018) overview of ELF pragmatics highlighted the use of pragmatic strategies in ELF interactions. The ability of a speaker to adapt to the context and the participant, as well as the ability to use various communicative strategies to preempt and solve comprehension problems, is a significant part of his pragmatic competence (Murray, 2012; Taguchi \& Ishihara, 2018). Pragmatics research emphasizes ELF interactions, mainly focusing on the discursive structure and communicative resources.

ELF interactions reveal the variable nature of discursive structures with relevant repairs. Discursive structures in ELF interactions is uncommon when compared with those in the interaction of native English speakers, including topic conversation, which is relatively common in the ELF context (Meierkord, 2002), cooperative overlap, code-switching (Cogo, 2009; Hülmbauer, 2009) and other linguistic phenomena. House (2003) found that ELF users often prefer some conjunctions of sentences such as "and" and "but" at the beginning of the conversation, but rarely use expressions such as "yes" and "I see" that indicate interpersonal meaning. As cooperation and competition co-exist in the ELF context, both parties will generally seek to avoid difficulties and misunderstandings in the process (Pitzl, 2005; Murray, 2012). Strategies or devices such as explicit strategies, comprehension checks, confirmation checks, clarification requests are common in ELF interactions (cf. Björkman, 2014). Svennevig (2008) found that repairs in ELF interactions generally involve the source of the topic and are all aimed at solving problems in the delivery and comprehension of the message. As for types of modification, the other-initiated repair, which tends to threaten the facework of the other party, appears more frequently in ELF interactions, and the purpose of this repair is generally to ensure the accurate and effective delivery of information (Ran \& Yang, 2015), which suggests that the clear delivery of information is the priority in ELF interactions. Further, Cogo and Dewey (2012) found that if a specific piece of information is particularly significant to the current communication, participants will use explicit means to avoid the potential of conflicts. When contradictions occur, ELF users will employ both marked and unmarked means to express their views in a different way (Angouri, 2012).

Communicative resources in the ELF context are characterized by multiplicity. Traditional views hold that culture takes precedence over communication, involving national groups with common characteristics (Piller, 2011). In this regard, traditional research seeks to resolve various conflicts and barriers in language use from a static and contrastive perspective. However, a "third space" culture will emerge in intercultural communication positioned in the ELF context, that is, "interculture" (Kecskes, 2013). The multiplicity of the ELF context means that the "interculture" is neither completely equivalent to the culture to which the speaker is attached nor to the native English culture (Kecskes, 2013). Rather, "interculture" is the dynamic interaction of different cultures instead of the mere comparison and contrast of cultures, which is referred to as a "cross-culture" perspective. Non-native English speakers from different linguistic and cultural backgrounds have become the main body of English usage; that is, English has gradually become "the language of others" (Jenkins, 2015, p. 52). "My English" (Kohn, 2011), which reflects the ways of self-communication and socio-cultural identity, shows that English acquisition is a social-cognitive process of constructing communication, which is the need and result of the pragmatic features of language use (Kecskes, 2014, p. 5), rather than a simple replication in a one-way context (Kohn, 2011, p. 79). Mauranen (2007, p. 244) found that the ELF context is characterized by the interaction and co-existence of multiple cultures. In other words, its function reflects the interaction and coordination of contexts between ELF participants, which is the crux to distinguish ELF interactions from intracultural communication, accordingly accounting for different expressions based on pragmatic competence. This is the inevitable result of the interaction between multilingual cultures in the ELF context, which is not only a simple combination and presentation of different discursive patterns among speakers, but also requires constant coordination, competition, adjustment, and re-coordination, emerging into various dynamic manifestations and 
diversified integration phenomena (Baker, 2015, p. 53). ELF users actively construct temporary speech communities in their interactions, and the initiative, as well as the creativity of "the English of others" in the ELF context, has become the pragmatic marker of otherization, so ELF users may construct what is not completely equivalent to native English.

\subsection{English as a Business Lingua Franca}

\subsubsection{BELF: An Overview}

English as a business lingua franca (BELF), originating from ELF, refers to the English used by non-native English speakers in business communication to accomplish specific tasks (Louhiala-Salminen et al., 2005, pp. 403-404). Louhiala-Salminen et al. (2005) point out that there are no fixed speakers of BELF interactions as BELF is neutral and shared. BELF, similar to ELF in other contexts, has no entity and is regarded as a language function, language practice, or mode of communication rooted in intercultural communication (cf. Mackenzie, 2014; Kecskes, 2015), which is highly dynamic emergent (Kecskes, 2013), inclusive, and hybrid (Kankaanranta \& Louhiala-Salminen, 2013). Specifically, BELF users make creative use of their native cultural knowledge and language resources to create common ground and achieve communicative goals (Kecskes, 2013; Liu \& Liu, 2017). It is not uncommon that BELF users seek and create emergent common ground in actual situational contexts, which serve as existing knowledge for later business. BELF research also questions the bias existing in traditional applied linguistics and intercultural communication studies and abandons the traditional notion that cultural differences and linguistic barriers have a negative impact on communication (Charles, 2007). Instead, it combines the characteristics of intercultural communication with those of business organizations (Liu \& Ran, 2019), and promotes meaning production and comprehension in the communication practice.

The communicative process is full of uncertainty in the BELF context (cf. Kankaanranta \& Louhiala-Salminen, 2013). As is mentioned, BELF users often make creative use of linguistic resources to accomplish tasks within the context of a business organization. BELF participants are generally highly mobile and they construct a temporary language community for a specific task or purpose and may bring the influence of their native cultures into it. Temporary knowledge that is neither completely equivalent to the speaker's native culture nor English culture will emerge, which is the inevitable result of multicultural interaction (Kecskes, 2013). A speech community can form relatively stable group rituals during the interaction, depending on factors such as business activities where these BELF users have been involved, the shared industry knowledge they hold, and the length of time over which the two parties have established the business relationship (Kankaanranta \& Planken, 2010).

\subsubsection{BELF and Pragmatics}

Pragmatics research on BELF interactions focuses on the influence of business contexts on language use and other factors that affect communication. Similar to other institutional discourses, success and failure co-exist in BELF interactions. Kecskes (2013) argues that pragmatic issues in BELF interactions are worth exploring, and pragmatics studies in the BELF context are mostly concerned with differences between speakers from different cultural backgrounds, and social values (e.g., Kankaanranta \& Lu, 2013). Du-Babcock (2013) holds that the development of pragmatic competence is influenced by the knowledge of the cultural background and language levels, such as knowledge of multiculturalism, business knowledge, and global communication skills (cf. Kankaanranta \& Planken, 2010; Kankaanranta \& Louhiala-Salminen, 2013). Pragmatic features of BELF interactions are further evaluated as follows.

Win-win cooperation is the primary goal of BELF interactions. The communication of meaning and the completion of tasks in BELF interactions can measure the effectiveness of communication (Firth, 1996; Kecskes, 2013). That is to say, the primary goal of communication is for BELF users to efficiently complete tasks through cooperation (Kankaanranta \& Planken, 2010, p. 381). However, due to different English levels and cultural backgrounds, there is a lack of collective common ground between speakers (Kecskes, 2013), so BELF users tend to spend more time and energy conveying information to reach mutual understanding. BELF users do not expect the other party to possess proficient English skills, which is considered unrealistic in this specific context (e.g., Charles, 2007). The evaluation standard of successful communication does not lie in the extent to which the English language and social pragmatic rules are followed, but in whether the parties can reach mutual understanding, even in using expressions that deviate from native English linguistic and cultural norms. Driven by common goals and interests, BELF users will try to use various resources to seek and create emergent common ground (Kecskes, 2013), which reflects that communication emerges as various dynamic manifestations and diversified integration (cf. Seidlhofer, 2011; Cogo \& Dewey, 2012; Mauranen, 2012) in the process of mutual coordination, competition, adjustment and re-coordination (Baker, 2015, p. 53).

BELF interactions embody speakers' institutional identity and dynamic interpersonal relationships. Different 
from daily ELF interactions, BELF has significant institutional characteristics (Liu \& Ran, 2019). For example, in BELF meetings, the chairman has more power and responsibility in scheduling and topic arrangement, meaning clarification, and content negotiation (cf. Handford, 2010; Liu \& Liu, 2017). Different institutional identities lead to the imbalance of speakers' speech rights, which is related to professional background knowledge, cultural background differences, participants' language level and expression ability, organizational power, and interpersonal relationship history, etc (Louhiala-Salminen et al., 2005, p. 391). While BELF interactions are oriented towards the completion of tasks and the delivery of information, it does not mean that interpersonal relationships can be ignored in the context (Komori-Glatz, 2018). BELF interactions, compared with other interpersonal interactions, focus on the establishment and maintenance of harmonious relationships (Pullin, 2013). In many cases, they show a much higher degree of mutual understanding, tolerance, and support (Kankaanranta \& Louhiala-Salminen, 2013), intending to complete tasks as well as managing rapport in their relationships at the same time.

BELF users make innovative use of communicative resources. This kind of creativity or originality is generally an accommodating mechanism in order to maintain continuous communication on the spot (Carter, 2004, p. 98), rather than an intentional act. BELF research is no longer committed to identifying the common core features of English varieties, but explores the functionality, multiple interactivities, and innovation of the communicative process (Komori-Glatz, 2018); in other words, it focuses on how speakers in the business context from different linguistic backgrounds coordinate and adapt to each other, tolerate and even take advantage of multicultural differences, improve efficiency and complete tasks. BELF users make creative use of language resources, trying to convey information and adjust their language use according to the language level and professional background of speakers at any time, in order to create and expand the basis of common ground (Kecskes, 2013). In addition, the emergence of "interculture" shows that the mobility of BELF users, the cultural diversity, and the dynamism of the communicative process has become communicative resources, which provides a new contextual space for English speakers from different linguistic and cultural backgrounds to present or highlight their own cultures (Ran \& Yang, 2016). Language creativity in BELF interactions is reflected in the analyzability of language structure components and the temporary collocation of words (Liu \& Ran, 2019), so the expression and understanding of meaning are mostly based on literal meaning and contextual dependence.

\section{Pragmatic Competence and BELF Interactions}

\subsection{Pragmatic Competence}

Pragmatic competence can be traced back to linguistic competence proposed by Chomsky (1965), which refers to linguistic knowledge or intrinsic grammar of language users. Later, he acknowledged the intention of language use and proposed the concept of "pragmatic competence", meaning "the ability to understand how language relates to the context in which it is used" (Chomsky, 1980, p. 225), and advocated the separation of pragmatic competence from linguistic competence. It is because linguistic competence mainly refers to the grammatical knowledge of a certain language, while social factors of language use are beyond the scope of language study. Later, Hymes (1972) proposed the concept of communicative competence, which holds that people can properly use language in real social communication; in other words, the pragmatic awareness with communicative competence is regarded as the core. Based on a series of previous studies on pragmatic competence (cf. Canale \& Swain, 1980; Canale, 1983; Leech, 1983; Li, 1984; Bachman, 1990), Thomas (1983, 1995), positioning pragmatic competence in the English context, argues that pragmatic competence can be divided into pragmalinguistic competence and sociopragmatic competence. However, the grammatical competence, which pragmalinguistic competence depends on and related language resources it refers to, are all based on native English. Sociocultural resources on which sociopragmatic competence depends are also associated with the sociopragmatic conventions formed by native English speakers (Leung, 2005).

The multilingual cultural contextual features of BELF interactions determine that intercultural communication is bound to be different from intracultural communication within one single language and culture. The former is not only prone to significant differences in pronunciation, grammar, vocabulary, and representation and understanding of pragmatic information (Watterson, 2008, p. 378), but also displays different pragmatic preferences (Kecskes, 2013, p. 19) as well as cultural expectations (Björkman, 2014), which can easily lead to variability in language use (Dewey, 2009) and a high degree of unpredictability (Mauranen, 2007) and problems such as asymmetry in BELF interactions (Kaur, 2010; Björkman, 2014). Pragmatic competence in BELF interactions reflects how speakers use specific contextual clues to appropriately use language or derive contextual information to achieve successful communication (Ran \& Yang, 2015, 2016). Based on the general trend of English development, English has become the language of "others", which calls for attention to contextual variables of non-linguistic dimensions such as interpersonal rapport and intercultural mediation that 
BELF users dynamically develop pragmatic ability to adjust concerning cultural differences and specific contexts (Pennycook, 2010; Baker, 2011) while focusing on the transmission of linguistic information and developing interpersonal relationship management skills (Spencer-Oatey, 2008; Seidlhofer, 2009). Pragmatic competence in BELF interactions involves the capacity to use a variety of resources, both linguistic and nonlinguistic, to conjointly construct meaning (Kaur \& Birlik, 2021). BELF research accounts for the change of pragmatic research in the communicative context and communicative process. Therefore, basic pragmatic competence in English and related pragmatic characteristics in the intercultural context of BELF interactions have become a new area of pragmatics research.

\subsection{Interpersonal Pragmatic Competence in BELF Interactions}

The management of interpersonal relationships in the BELF context is unnecessarily positive rapport management, but it also includes the conflict management of the diversified discourse. Grounding Spencer-Oatey's (2008) rapport management model, the management of interpersonal relationships involves enhancing, maintaining, neglecting, and challenging rapport, which influences the delivery of information. BELF interactions concern not only the convergence and cooperation of information transmission, but also multiple discourses that may emerge in communication, leading to the pragmatic distance between BELF users or group differences (Knapp, 2011). Competitive discourse, as well as cooperative discourse, co-exists in BELF interactions, and they need to be identified and responded to as they are more manifested in the intercultural context. Given the unequal status of power, it becomes normal that debate and refutation may replace cooperation and collaboration, which is especially obvious in the BELF context in which power serves as the dominant factor. In addition, the appearance of laughter, jokes, teasing, and other emotive expressions is not always intended for building rapport in interpersonal relationships, but on occasion for interpersonal pragmatic problems and the threatening of facework between two parties, thus challenging interpersonal rapport (Jenks, 2012). In this regard, BELF users may adopt different interpersonal strategies, like politeness strategies, based on their intimacy, topic content, specific contexts, etc., and achieve rapport in interpersonal relationships through face maintenance (Walkinshaw \& Kirkpoatrick, 2014). Therefore, the management of interpersonal relationships reflects the interpersonal pragmatic competence in BELF interactions with dynamism and complexity.

The change of interpersonal relationships in BELF interactions also involves the dynamic negotiation and construction of identity. Identity, especially cultural identity, has become the focus of BELF research (Baker, 2015). Due to the linguistic and cultural diversity and intersecting nature of the BELF context, this particular interaction is no longer a simple process of information transmission, but a process of mutual acceptance, integration, transformation, and reconstruction (Liu \& Ran, 2019), which is manifested as the dynamic construction of cultural identity through language practice (Pennycook, 2007). This indicates that BELF has become a communicative resource for mapping and constructing participants' cultural identities (Seidlhofer, 2004). Accordingly, speakers from different linguistic and cultural backgrounds can maintain, coordinate and adjust or reconstruct their own cultural identity (Pölzl \& Seidlhofer, 2006; Sung, 2014). The identity characteristics of BELF users is also multi-dynamic (Baker, 2011), which reflects the significance of relational skills to manage interpersonal relationships (Spencer-Oatey, 2008; Seidlhofer, 2009). In other words, BELF users are to some extent dependent on the linguistic and cultural conventions of their mother tongue, and are prone to ethnocentric thoughts (Hult, 2010) and discursive behaviors that reflect the local culture. Therefore, BELF users will adopt appropriate interpersonal pragmatic strategies to reconstruct temporary and mutually accepted common intra-group identities while presenting identities of the local culture.

\subsection{Intercultural Pragmatic Competence in BELF Interactions}

BELF interactions mainly reveal speakers' intercultural pragmatic competence as they are situated in the intercultural context. Intercultural pragmatic competence in language use is reflected in the resource utilization, which not only gives priority to a simple, direct, and clear linguistic form, and a certain degree of creativity or originality, but also seeks and creates common ground in forming the emergent "interculture" (Kecskes, 2013).

The awareness of intercultural communication refers to the effective and appropriate interaction of knowledge, motivation, and skills from different backgrounds (Wiseman, 2003, p. 192). Effectiveness and appropriateness are the main criteria to measure speakers' ability of intercultural communication. To a certain degree, strategies or awareness of avoiding various information conflicts in intercultural communication are of dominant significance in the study of pragmatic competence, which emphasizes the understanding of the target culture as well as the assimilation of the native culture into the target culture (Liu \& Ran, 2019). In the BELF context, pragmatic competence studies have increasingly focused on the choice of pragmatic strategies (e.g., Jenkins, 2007, 2011; Seidlhofer, 2011; Cogo \& Dewey, 2012; Björkman, 2014) and the ability of mediation and 
cooperation in the intercultural context (Pennycook, 2010; Baker, 2011). Apart from the pragmatic competence at the level of information transmission, intercultural pragmatic competence also sheds light on the ability to build rapport in interpersonal relationships (Spencer-Oatey, 2008) to use language for the management of interpersonal relationships, echoing with interpersonal pragmatic competence. Therefore, intercultural pragmatics studies positioned in the BELF context tend to involve different aspects, including language selection, information construction, relationship interaction, and cultural mediation, etc.

Intercultural pragmatic competence is dynamic and dependent on the context, mainly reflected in the creative use of linguistic resources. Intercultural pragmatic competence is refined and illustrated by Liu and Ran (2019), which is targeted at speakers from different linguistic and cultural backgrounds. The choice of BELF is embodied in the selection and utilization of linguistic resources, the construction and delivery of information, the interactions of relationships, and the adjustment of adaptation of cultural and background knowledge. Intercultural pragmatic competence is proposed to highlight the adaptability and creativity of the dynamic adjustment between the language means chosen by both speakers and the context, affected by the "interculturality" generated by the interaction and integration of different cultures. In Intercultural Pragmatics, Kecskes (2013) re-examines pragmatic competence in intercultural communication, focusing on the impact of socio-cognitive factors and individual preferences of communicative subjects on pragmatic competence, specially positioned in the ELF context to explore the development of pragmatic competence in bilingual and multilingual contexts. The study of intercultural pragmatic competence from the perspective of intercultural pragmatics not only emphasizes the choice of linguistic means and pragmatic strategies (Björkman, 2014; Cogo \& Dewey, 2012), but also seeks to include speakers' mediation and mutual coordination of communicative content and process under the restriction of a specific context (Baker, 2011) and the ability to manage rapport in relationships (Pullin, 2013). In this regard, the pragmatic paradigm and social conventions of native English speakers are no longer the criteria for measuring and judging pragmatic competence in the BELF context (Liu \& Ran, 2019). In other words, pragmatic competence is no longer reflected as a top-down static prescriptive competence, but more as a complex and mixed system emerging in a bottom-up approach in BELF interactions.

\section{Implications}

\subsection{Pragmatic Competence and Pragmatic Strategies}

BELF interactions tend to be task-oriented or content-oriented. For speakers from different linguistic and cultural backgrounds, the effective delivery of information is the key to measuring the effectiveness of communication (cf. Firth, 1996). However, in discourse production and comprehension, there is often a lack of sufficient common ground between speakers in intercultural contexts (Kecskes, 2013). Therefore, pragmatic strategies aiming at the co-construction of information are often employed in BELF interactions, which reflects the dynamic pragmatic competence of speakers in this context. With regard to pragmatic competence, BELF users can make effective communication based on relevant pragmatic strategies. The skillful use of pragmatic strategies in meaning negotiation contributes to communicative effectiveness and constitutes "effective pragmatic act[s] in ELF" interactions (Taguchi \& Ishihara, 2018, p. 86).

From time to time, BELF users can still achieve successful communication with little or no misunderstanding and confusion despite insufficient common ground (cf. Kaur, 2010). It is mainly attributed to the strategy of the co-construction of information (Ran \& Yang, 2016) adopted to create common ground and clarify the information in the actual situational context. Different pragmatic strategies may occur in different stages of communication, such as the resolution strategy (Cogo \& Dewey, 2012) in the comprehension stage of discourse, and the preempting strategy (Mauranen, 2006) in the face of potential difficulties in understanding the discursive meaning. Other similar strategies include explicitness strategies such as self-clarification, self-correction, repetition, retelling, collaborative completion, and cooperative overlap (cf. Cogo \& Dewey, 2012; Deterding, 2013). Firth (1996) also found that BELF users would skip unclear words and utterances and adopt strategies such as "let-it-pass" and "wait-and-see" (Cogo \& Dewey, 2012) to avoid communicative barriers. In addition, BELF users also try to present the information more clearly, making the intention clearer to the listener in the topic negotiation and management with meta-discourse strategies (Mauranen, 2007, 2010; House, 2013). Similarly, metapragmatic expressions also serve as pragmatic strategies to create common ground (Liu \& Liu, 2017) and adjust salience (Liu \& Liu, 2021) in the BELF context. These strategies suggest that successful BELF interactions are featured by the joint involvement and interaction of both parties by creating common ground to achieve mutual understanding of information and solving problems and potential obstacles.

The BELF context is a double-edged sword. It not only increases the complexities of communication, but also provides diversified contextual resources for interactions. Thus, BELF users are expected to make a dynamic 
selection and use proper pragmatic strategies, such as explicit code-switching (Cogo, 2010; Pietikäinen, 2014) and implicit cognate effect (cf. Hülmbauer, 2009). While highlighting the content of the discourse, they also mark or construct the cultural identity of the communicative subject and therefore, consolidate the in-group relationship between speakers (Seidlhofer, 2009). It is not difficult to find that judging from the actual situational context, BELF participants will creatively bridge language gaps that are different from native English, which reflects various phenomena of language use in BELF interactions and is a manifestation of discursive management (Mauranen, 2010). The co-construction of information in the BELF context is not only influenced by misunderstanding or confusion, but also by the emergence of hybrid language forms in the interaction so that BELF users will construct the contextual common ground (Kecskes, 2013), or make the specific pragmatic information clearer to achieve mutual understanding of the discourse (Ran \& Yang, 2016). The interactive synergy of contextualized pragmatic strategies is therefore reflected in BELF interactions.

In the presence of considerable variability in language form and use (Firth, 2009; Seidlhofer, 2011), it is critical for the speaker's ability to use a range of pragmatic strategies to convey and interpret meaning successfully. Skillful use of pragmatic strategies constitutes an essential part of one's pragmatic competence (Kaur \& Birlik, 2021). The diversity of BELF interactions enables participants to choose proper pragmatic strategies by identifying pragmatic clues with information from the context. The use of pragmatic strategies in the BELF context helps to effectively avoid some potential problems that may emerge in the interaction and settle some communicative barriers that have occurred or may occur in meaning comprehension.

\subsection{Pragmatic Competence and Pragmatic Awareness}

The pragmalinguistic and sociopragmatic change triggered by the contextual features and language use of BELF interactions gives rise to the change in the communicative process and pragmatic competence. Different from the single context of language, the pragmalinguistic and sociopragmatic paradigm that emerges in this specific context challenges the traditional pragmatic competence of the dominated standard of native English (Ran \& Yang, 2016) and provides new insight into the institutional discursive characteristics of BELF interactions and the development in pragmatic awareness.

In general, BELF teaching and learning have emphasized the pragmalinguistic and sociopragmatic paradigm and their social conventions attached to native English speakers. However, a significant theoretical flaw is obvious when it comes to this single reference: it is easy to equate language with specific codes and social conventions of language use with fixed rules (Baker, 2015, p. 138). Therefore, English pragmatic competence should not be limited to native speakers' conventions outlined by editors and trainers of textbooks (Leung, 2005). The concept of pragmatic competence in BELF interactions has evolved "from the individualistic and stable view to a more dynamic, agency-oriented view" (Taguchi \& Ishihara, 2018, p. 82), which indicates that pragmatic competence is not statically prescriptive but dynamically descriptive.

The globalization of English use makes it necessary for us to reconsider and reconstruct the reference standards of pragmatic competence and pragmatic awareness in the actual situational context. It is more significant in the diversity and intersection of linguistic and cultural backgrounds in the BELF context (Kecskes, 2013), as well as the otherization of BELF users. Pragmatic competence is both temporary and constructive, including interpersonal relationship management and identity construction among BELF users, in addition to the effective transmission and understanding of linguistic and pragmatic information. For this reason, many scholars (e.g., House, 2003; He, 2011; Jenkins, 2011) point out that the single pragmatic competence that follows native English is no longer sufficient to explain and promote effective BELF interactions.

The reconstruction of pragmatic competence in BELF interactions requires a reinterpretation of relationships, pointing to speakers' intercultural pragmatic awareness. Static cultural pragmatics over-simplifies the complex adaptive relationship between culture, language, and communication, and thus fails to interpret the intersectionality and dynamics of multilingual cultures embodied in BELF interactions (Liu \& Ran, 2019), resulting in the relationship between culture and communication irrelevant contextual constraints (Baker, 2015). From an intercultural perspective, BELF interactions, with the integration of different languages and cultures, focus on how speakers in the BELF context create common ground and achieve cooperation and collaboration (Kecskes, 2013). Cross-cultural awareness in pragmatics is regarded as comparing similarities and contrasting and differences of linguistic and cultural knowledge on the premise of pragmatic competence, while intercultural awareness of BELF interactions is more complicated and dynamic than the linear dependent relationship between culture and language, with the emphasis placed on the mutual harmony and synergy between multiple contextual factors and temporary established relationships (cf. Baker, 2015).

The key to intercultural business communication is dynamic negotiation and adjustment for lack of pre-existing 
and sufficient common ground and cognitive space among BELF users (Baker, 2011, p. 203; Liu \& Ran, 2019). The content of negotiation in BELF interactions not only refers to the form and meaning of language, but also includes sociopragmatic information on the non-linguistic level such as social identity, cultural reference, and cultural behavior (Liu \& Ran, 2019). Traditional concepts of pragmatic competence pay special attention to pronunciation, vocabulary, syntax, and other forms of language use, neglecting what is embodied in the context of the diversified communicative process, and the ability to manage interpersonal relationships in intercultural contexts (Ran \& Yang, 2016). Cultural awareness, pragmatic awareness, and other elements are of great significance in the BELF context. Hence, pragmatic awareness based on pragmatic competence in BELF interactions shifts from the unidirectional linguistic dimension to the hyper-linguistic dimension of social pragmatics (e.g., relational management and identity construction from the interpersonal perspective), which conforms to the multi-perspective integration that contemporary pragmatics emphasizes language use and communicative process to construct meaning in interactions.

\section{Concluding Remarks}

English is widely shared by non-native English speakers, which contributes to the unprecedented change in the social role of English as well as the emergence of (B)ELF interactions. The (B)ELF context and pragmatic features it elicits have accounted for a new research perspective different from the traditional view of pragmatic competence. The perception of pragmatic competence that English learners acquire and use the language to meet the standard of native English has been challenged to a large context. In other words, the paradigm of pragmatic competence based on the linguistic and cultural norms of native English is no longer applicable to the interpretation of (B)ELF interactions. Hence, the connotation of pragmatic competence should not be confined to what is normal in the native English context; instead, research on pragmatic competence seeks to involve interpersonal pragmatic competence and intercultural pragmatic competence in a specific context.

Different from monolingual and intracultural communication, BELF interactions, situated in the intercultural context, are influenced by its institutional discursive features in terms of intention, resources integration, knowledge construction, and communicative process. Based on the contextualized characteristics of BELF interactions, this paper reviews the performance of pragmatic competence in this context, presenting interpersonal pragmatic competence and intercultural pragmatic competence, discusses the necessity of reconstructing an appropriate perception of pragmatic competence, and points out the significance of connecting pragmatic competence to pragmatic strategies and pragmatic awareness. However, it should be noticed that theories and practices concerning foreign language teaching, learning, and testing generally fail to keep up with those new changes and features in the development from EFL to ELF, which English teaching and research should face in the long run. Future English teaching practice and research can focus on the communicative needs from the perspective of pragmatics and raise practitioners' and researchers' awareness of pragmatic strategies to promote pragmatic competence via authentic input and opportunities for realistic BELF interactions through training. Whether or how English can be taught as a lingua franca and what is reflected in the pragmatic competence in the BELF contexts still need further empirical investigation.

\section{References}

Alptekin, C. (2010). Redefining multi-competence for Bilingualism and ELF. International Journal of Applied Linguistics, 20(1), 95-110. https://doi.org/10.1111/j.1473-4192.2009.00230.x

Alptekin, C. (2013). English as a lingua franca through a usage-based perspective: Merging the social and the cognitive in language use. Language Culture \& Curriculum, 26(2), 197-207. https://doi.org/10.1080/07908318.2013.810224

Angouri, J. (2012). Managing disagreement in problem solving meeting talk. Journal of Pragmatics, 44(12), 1565-1579. https://doi.org/10.1016/j.pragma.2012.06.010

Bachman L. (1990). Fundamental Considerations in Language Testing. Oxford: Oxford University Press.

Baker, W. (2011). Intercultural awareness: Modelling an understanding of cultures in intercultural communication through English as a lingua franca. Language and Intercultural Communication, 11(3), 197-214. https://doi.org/10.1080/14708477.2011.577779

Barker, W. (2015). Culture and Identity through English as a Lingua Franca. Berlin: Walter de Gruyter. https://doi.org/10.1515/9781501502149

Björkman, B. (2008). 'So where we are?' Spoken lingua franca English at a technical university in Sweden. English Today, 24(2), 35-41. https://doi.org/10.1017/S0266078408000187 
Björkman, B. (2011). Pragmatic strategies in English as an academic lingua franca: Ways of achieving communicative effectiveness. Journal of Pragmatics, 43(4), 950-964. https://doi.org/10.1016/j.pragma.2010.07.033

Björkman, B. (2014). An analysis of polyadic English as a lingua franca (ELF) speech: A communicative strategies framework. Journal of Pragmatics, 66, 122-138. https://doi.org/10.1016/j.pragma.2014.03.001

Canagarajah, S. (2007). Lingua franca English, multilingual communities, and language acquisition. The Modern Language Journal, 91(1), 923-939. https://doi.org/10.1111/j.1540-4781.2007.00678.x

Canale, M. (1983). From communicative competence to communicative language pedagogy. In J. Richards \& R. Schmidt (Eds.), Language and Communication (pp. 2-27). London: Longman.

Canale, M., \& Swain, M. (1980). Theoretical bases of communicative approaches to second language teaching and testing. Applied Linguistics, 1(1), 1-47. https://doi.org/10.1093/applin/I.1.1

Carter, R. (2004). Language and Creativity: The Art of Common Talk. Milton Park: Routledge.

Charles, M. (2007). Language matters in global communication. Journal of Business Communication, 44(3), 260-282. https://doi.org/10.1177/0021943607302477

Chen, X., \& Li, M. (2015). New solutions to Pragmatic Failures in the Context of English as an international lingua franca. Foreign Language and Foreign Language Teaching, 2, 7-12. https://doi:10.13458/j.cnki.flatt.004064.

Chomsky, N. (1965). Syntactic Structures. London: Mouton.

Chomsky, N. (1980). Rules and Representations. Oxford: Basil Blackwell. https://doi.org/10.1017/S0140525X00001515

Cogo, A. (2009). Accommodating difference in ELF conversations: A study of pragmatic strategies. In A. Mauranen \& E. Ranta (Eds.), English as a Lingua Franca: Studies and Findings (pp. 254-273). Newcastle: Cambridge Scholars Publishing.

Cogo, A. (2010). Strategic use and Perceptions of English as a Lingua Franca. Poznań Studies in Contemporary Linguistics, 46(3), 295-312. https://doi.org/10.2478/v10010-010-0013-7

Cogo, A., \& Dewey, M. (2012). Analyzing English as a Lingua Franca: A Corpus-driven Investigation. London $\&$ New York: Continuum.

Cogo, A., \& House, J. (2018). The pragmatics of ELF. In J. Jenkins, W. Baker \& M. Dewey (Eds.), The Routledge handbook of English as a lingua franca (pp. 210-223). Abingdon, UK: Routledge. https://doi.org/10.4324/9781315717173-18

Deterding, D. (2013). Misunderstanding in English as a Lingua Franca. Berlin: Mouton de Gruyter. https://doi.org/10.1515/9783110288599

Dewey, M. (2007). English as a lingua franca: An interconnected perspective. International Journal of Applied Linguistics, 17(3), 332-354. https://doi.org/10.1111/j.1473-4192.2007.00177.x

Dewey, M. (2009). English as a lingua franca. In A. Mauranen \& E. Ranta (Eds.), English as a Lingua Franca: Studies and Findings (pp. 60-83). Newcastle: Cambridge Scholars Publishing.

Ferguson, G. (2009). Issues in researching English as a lingua franca: A conceptual enquiry. International Journal of Applied Linguistics, 19(2), 117-135. https://doi.org/10.1111/j.1473-4192.2009.00225.x

Firth, A. (1996). The discursive accomplishment of normality: On 'lingua franca' English and conversational analysis. Journal of Pragmatics, 26(2), 237-259. https://doi.org/10.1016/0378-2166(96)00014-8

Firth, A. (2009). The lingua franca factor. Intercultural Pragmatics, 6, 147-170. https://doi.org/10.1515/IPRG.2009.009

Graddol, D. (2006). English Next: Why Global English May Mean the End of 'English as a Foreign Language'. London: British Council.

Handford, M. (2010). The Language of Business Meetings. Cambridge: Cambridge University Press. https://doi.org/10.1017/CBO9781139525329

House, J. (1999). Misunderstanding in intercultural communication: Interactions in English as a lingua franca and the myth of mutual intelligibility. In C. Gnutzmann (Ed.), Teaching and Learning English as a Global Language (pp. 73-89). Tübingen: Stauffenburg. 
House, J. (2003). English as a lingua franca: A threat to multilingualism. Journal of Sociolinguistics, 7(4), 556-578. https://doi.org/10.1111/j.1467-9841.2003.00242.x

House, J. (2009). Introduction: The pragmatics of English as a lingua franca. Intercultural Pragmatics, 6(2), 141-145. https://doi.org/10.1515/IPRG.2009.008

House, J. (2013). Developing pragmatic competence in English as a lingua franca: using discourse markers to express (inter)subjectivity and connectivity. Journal of Pragmatics, 59, 57-67. https://doi.org/10.1016/j.pragma.2013.03.001

Hülmbauer, C. (2009). "We don't take the right way. We just take the way that we think you will understand"-The shifting relationship of correctness and effectiveness in ELF communication. In A. Mauranen \& E. Ranta (Eds.), English as a Lingua Franca: Studies and Findings (pp. 323-347). Newcastle upon Tyne: Cambridge Scholars Publishing.

Hult, F. (2010). Directions and Prospects for Educational Linguistics. London: Springer. https://doi.org/10.1007/978-90-481-9136-9

Hymes, D. H. (1972). On communicative competence. In J. B. Pride \& J. Holmes (Eds.), Sociolinguistics: Selected Readings (pp. 269-293). Harmondsworth, Middlesex: Penguin.

Jenkins, J. (2000). The Phonology of English as an International Language: New Models, New Norms, New Goals. Oxford: Oxford University Press.

Jenkins, J. (2006). Current perspectives on teaching world Englishes and English as a lingua franca. TESOL Quarterly, 40(1), 157-181. https://doi.org/10.2307/40264515

Jenkins J. (2007). English as a Lingua Franca: Attitude and Identity. Oxford: Oxford University Press.

Jenkins, J. (2009). English as a lingua franca: Interpretations and attitudes. World Englishes, 28(2), 200-207. https://doi.org/10.1111/j.1467-971X.2009.01582.x

Jenkins J. (2011). Accommodating (to) ELF in the international university. Journal of Pragmatics, 43(4), 925-936. https://doi.org/10.1016/j.pragma.2010.05.011

Jenkins, J. (2014). English as a Lingua Franca in the International University: The Politics of Academic English Language Policy. New York \& London: Routledge. https://doi.org/10.4324/9780203798157

Jenkins, J. (2015). Repositioning English and multilingualism in English as a lingua franca. Englishes in Practice, 2(3), 49-85. https://doi.org/10.1515/eip-2015-0003

Jenkins, J., Cogo, A., \& Dewey, M. (2011). Review of developments in research into English as a lingua franca. Language Teaching, 44(3), 281-315. https://doi.org/10.1017/S0261444811000115

Jenks, C. J. (2012). Doing being reprehensive: Some interactional features of English as a lingua franca in a chat room. Applied Linguistics, 33(4), 386-405. https://doi.org/10.1093/applin/ams014

Kankaanranta, A., \& Louhiala-Salminen, L. (2013). "What language does global business speak?"-The concept and development of BELF. Ibérica, 26(26), 17-34.

Kankaanranta, A., \& Lu, W. (2013). The evolution of English as the business lingua franca: Signs of convergence in Chinese and Finnish professional communication. Journal of Business \& Technical Communication, 27(3), 288-307. https://doi.org/10.1177/1050651913479919

Kankaanranta, A., \& Planken, B. (2010). BELF competence as business knowledge of internationally operating business professionals. Journal of Business Communication, 47(4), 380-407. https://doi.org/10.1177/0021943610377301

Kaur, J. (2010). Achieving mutual understanding in world Englishes. World Englishes, 29(2), 192-208. https://doi.org/10.1111/j.1467-971X.2010.01638.x

Kaur, J., \& Birlik, S. (2021). Communicative effectiveness in BELF (English as a business lingua franca) meetings: 'Explaining' as a pragmatic strategy. The Modern Language Journal, 105(3), 623-638. https://doi.org/10.1111/modl.12717

Kecskes, I. (2013). Intercultural Pragmatics. Oxford: Oxford University Press. https://doi.org/10.1093/acprof:oso/9780199892655.001.0001

Kecskes, I. (2014). About Bilingual Pragmatic Competence. Modern Foreign Language, 01, 1-22. https://doi.org/10.4103/2348-0548.124830 
Kecskes, I. (2015). How does pragmatic competence develop in bilinguals? International Journal of Multilingualism, 12(4), 419-434. https://doi.org/10.1080/14790718.2015.1071018

Knapp, A. (2011). Using English as a lingua franca for (mis-)managing conflict in an international university context: An example from a course in engineering. Journal of Pragmatics, 43(4), 978-990. https://doi.org/10.1016/j.pragma.2010.08.008

Kohn, K. (2011). ELF and the standard English misunderstanding. In A. DeHouwer \& A. Wilton (Eds.), English in Europe Today (pp. 72-94). Amsterdam: John Benjamins. https://doi.org/10.1075/aals.8.06koh

Komori-Glatz, M. (2018). Conceptualising English as a business lingua franca. European Journal of International Management, 12(1/2), 46-61. https://doi.org/10.1504/EJIM.2018.10009389

$\mathrm{Ku}, \mathrm{H} .$, \& Zussman, A. (2010). Lingua franca: The role of English in international trade. Journal of Economic Behavior \& Organization, 75(2), 250-260. https://doi.org/10.1016/j.jebo.2010.03.013

Leech, G. (1983). Principles of Pragmatics. London: Longman.

Leung, C. (2005). Convivial communication: Recontextualizing communicative competence. International Journal of Applied Linguistics, 15(2), 119-144. https://doi.org/10.1111/j.1473-4192.2005.00084.x

Li, X. (1984). In defence of the communicative approach. ELT Journal, 38(1), 2-13. https://doi.org/10.1093/elt/38.1.2

Liu, P., \& Liu, H. (2017). Creating common ground: The role of metapragmatic expressions in BELF meeting interactions. Journal of Pragmatics, 107, 1-15. https://doi.org/10.1016/j.pragma.2016.10.006

Liu, P., \& Liu, H. (2021). Salience adjusting: Metapragmatic expressions in complaint responses. Journal of Pragmatics, 176, 150-163. https://doi.org/10.1016/j.pragma.2021.01.003

Liu, P., \& Ran, Y. (2019). Intercultural pragmatic competence in BELF interactions. Foreign Language Teaching Theory and Practice, 4, 8-16. https://doi.org/10.1088/1475-7516/2019/04/002

Louhiala-Salminen, L., Charles, M., \& Kankaanranta, A. (2005). English as a lingua franca in Nordic corporate mergers: Two case companies. English for Specific Purposes, 24(4), 401-421. https://doi.org/10.1016/j.esp.2005.02.003

Mackenzie, I. (2014). English as a Lingua Franca: Theorizing and Teaching English. New York: Routledge Taylor \& Francis Group. https://doi.org/10.4324/9781315890081

Mauranen, A. (2006). Signaling and preventing misunderstanding in English as lingua franca communication. International Journal of the Sociology of Language, 177, 123-150. https://doi.org/10.1515/IJSL.2006.008

Mauranen, A. (2007). Hybrid voices: English as the lingua franca of academics. In K. Flottum (Ed.), Languages and Discipline Perspectives on Academic Discourse (pp. 244-259). Newcastle: Cambridge Scholar Publishing.

Mauranen, A. (2010). Discourse reflexivity—a discourse universal? The case of ELF. Nordic Journal of English Studies, 9(2), 13-40. https://doi.org/10.35360/njes.216

Mauranen, A. (2012). Exploring ELF: Academic English Shaped by Non-native Speakers. Cambridge: Cambridge University Press.

Mckay, S. L. (2010). Toward an appropriate eil pedagogy: re-examining common elt assumptions. International Journal of Applied Linguistics, 13(1), 1-22. https://doi.org/10.1111/1473-4192.00035

Meierkord, C. (2002). "Language stripped bare" or "linguistic masala"? Culture in lingua franca communication. In K. Knapp \& C. Meierkord (Eds.), Lingua Franca Communication (pp. 109-133). Frankfurt: Peter Lang.

Murray, N. (2012). English as a lingua franca and the development of pragmatic competence. ELT Journal, 66(3), 318-326. https://doi.org/10.1093/elt/ccs016

Nielsen, T. H. (2019). Norwegian business professionals' need for and use of English as a business lingua franca (BELF) in multinational corporations. Hermes (Journal of Language and Communication in Business), 59(1), 109-122. https://doi.org/10.7146/hjlcb.v59i1.117020

Park, J. S., \& Wee, L. (2011). A practice-based critique of English as a lingua franca. World Englishes, 30(3), 360-374. https://doi.org/10.1111/j.1467-971X.2011.01704.x

Pennycook, A. (2007). Global Englishes and Transcultural Flows. London: Routledge. https://doi.org/10.4324/9780203088807 
Pennycook, A. (2010). Language as a Local Practice. London: Routledge. https://doi.org/10.4324/9780203846223

Pietikäinen, K. (2014). ELF couples and automatic code-switching. Journal of English as a Lingua Franca, 3(1), 1-26. https://doi.org/10.1515/jelf-2014-0001

Piller, I. (2011). Intercultural Communication: A Critical Introduction. Edinburgh: Edinburgh University Press.

Pitzl, M. (2005). Non-understanding in English as a lingua franca: Examples from a business context. Vienna English Working Papers, 2, 50-71.

Pölzl, U., \& Seidlhofer, B. (2006). In and on their own terms: The "habitat factor" in English as a lingua franca interactions. International Journal of the Sociology of Language, 177, 151-176. https://doi.org/10.1515/IJSL.2006.009

Prodromou, L. (2007). Is ELF a variety of English? English Today, 23(2), 47-53. https://doi.org/10.1017/S0266078407002088

Pullin, P. (2013). Achieving "comity": The role of linguistic stance in business English as a lingua franca (BELF) meetings. Journal of English as a Lingua Franca, 2(1), 1-23. https://doi.org/10.1515/jelf-2013-0001

Quirk, R. (1985). The English language in a global context. In R. Quirk \& H. G. Widdowson (Eds.), English in the World: Teaching and Learning the Languages and Literatures (pp. 1-6). Cambridge: Cambridge University Press.

Ran, Y., \& Yang, Q. (2015). A new approach to pragmatic competence in the ELF context. The Foreign Language Society, 5, 10-17. https://doi.org/10.1088/1475-7516/2015/05/004

Ran, Y., \& Yang, Q. (2016). Pragmatic Competence and its Reconstruction in the context of International Lingua franca of English. Foreign Language Teaching and Research, 2, 287-299, 321. https://doi.org/10.1088/1475-7516/2016/02/011

Seidlhofer, B. (2004). Research perspectives on teaching English as a lingua franca. Annual Review of Applied Linguistics, 24(1), 209-239. https://doi.org/10.1017/S0267190504000145

Seidlhofer, B. (2009). Accommodation and the idiom principle in English as a lingua franca. Intercultural Pragmatics, 6(2), 195-215. https://doi.org/10.1515/IPRG.2009.011

Seidlhofer, B. (2011). Understanding English as a Lingua Franca. Oxford: Oxford University Press.

Sewell, A. (2012). English as a lingua franca: Ontology and ideology. ELT Journal, 67(1), 3-10. https://doi.org/10.1093/elt/ccs061

Spencer-Oatey, H. (2008). Culturally Speaking: Culture, Communication and Politeness Theory (2nd ed.). London: Continuum.

Sung, C. (2014a). English as a lingua franca and global identities: Perspectives from four second language learners of English in Hong Kong. Linguistics \& Education, 26, 31-39. https://doi.org/10.1016/j.linged.2014.01.010

Sung, C. (2014b). Global, local or global? Identities of L2 learners in English as a lingua franca communication. Language Culture \& Curriculum, 27(1), 43-57. https://doi.org/10.1080/07908318.2014.890210

Svennevig, J. (2008). Trying the easiest solution first in other-initiation of repair. Journal of Pragmatics, 40(2), 333-348. https://doi.org/10.1016/j.pragma.2007.11.007

Taguchi, N., \& Ishihara, N. (2018). The pragmatics of English as a lingua franca: Research and pedagogy in the era of globalization. Annual Review of Applied Linguistics, 37, 80-101. https://doi.org/10.1017/S0267190518000028

Thomas, J. (1993). Cross-cultural pragmatic failure. Applied Linguistics, 4(2), 91-112. https://doi.org/10.1093/applin/4.2.91

Thomas, J. (1995). Managing in Interaction. London: Longman.

Walkinshaw, I., \& Kirkpatrick, A. (2014). Mutual face preservation among Asian speakers of English as a lingua franca. Journal of English as a Lingua Franca, 3(2), 269-291. https://doi.org/10.1515/jelf-2014-0017

Wang, Y. (2013). Non-conformity to ENL norms: A perspective from Chinese English users. Journal of English as a Lingua Franca, 2(2), 255-282. https://doi.org/10.1515/jelf-2013-0015

Watterson, M. (2008). Repair of non-understanding in English in international communication. World Englishes, 
27(3-4), 378-406. https://doi.org/10.1111/j.1467-971X.2008.00574.X

Wen, Q. (2012). English as a lingua franca: A pedagogical perspective. Journal of English as a Lingua Franca, 1(2), 371-376. https://doi.org/10.1515/jelf-2012-0024

Wiseman, R. L. (2003). Intercultural communication competence. In W. B. Gudykunst (Ed.), Cross-Cultural and Intercultural Communication (pp. 191-208). Thousand Oaks: Sage.

\section{Copyrights}

Copyright for this article is retained by the author, with first publication rights granted to the journal.

This is an open-access article distributed under the terms and conditions of the Creative Commons Attribution license (http://creativecommons.org/licenses/by/4.0/). 